IZA DP No. 4518

A Cost-Benefit Analysis of Early Childhood Intervention: Evidence from a Randomised Evaluation of a Parenting Programme

Donal O'Neill

October 2009 


\title{
A Cost-Benefit Analysis of Early Childhood Intervention: Evidence from a Randomised Evaluation of a Parenting Programme
}

\author{
Donal O'Neill \\ NUI Maynooth \\ and IZA
}

Discussion Paper No. 4518

October 2009

\author{
IZA \\ P.O. Box 7240 \\ 53072 Bonn \\ Germany \\ Phone: +49-228-3894-0 \\ Fax: +49-228-3894-180 \\ E-mail: iza@iza.org
}

Any opinions expressed here are those of the author(s) and not those of IZA. Research published in this series may include views on policy, but the institute itself takes no institutional policy positions.

The Institute for the Study of Labor (IZA) in Bonn is a local and virtual international research center and a place of communication between science, politics and business. IZA is an independent nonprofit organization supported by Deutsche Post Foundation. The center is associated with the University of Bonn and offers a stimulating research environment through its international network, workshops and conferences, data service, project support, research visits and doctoral program. IZA engages in (i) original and internationally competitive research in all fields of labor economics, (ii) development of policy concepts, and (iii) dissemination of research results and concepts to the interested public.

IZA Discussion Papers often represent preliminary work and are circulated to encourage discussion. Citation of such a paper should account for its provisional character. A revised version may be available directly from the author. 
IZA Discussion Paper No. 4518

October 2009

\begin{abstract}
A Cost-Benefit Analysis of Early Childhood Intervention: Evidence from a Randomised Evaluation of a Parenting Programme*

A number of researchers and policy makers have recently argued that the most effective way of dealing with long-run disadvantage and the intergenerational transmission of poverty is through early childhood intervention and in particular policies aimed at supporting the family in early childhood development. In this paper we carry out a randomised evaluation of one such programme aimed at improving the skills and parenting strategies of parents, particularly those who find their child's behaviour difficult or challenging. Our evaluation shows that the treatment significantly reduced behavioural problems in young children when measured 6 months after the intervention. Furthermore our detailed cost analysis, combined with a consideration of the potential long-run benefits associated with the programme, suggest that the long-run rate of return to society from this programme is likely to be relatively high.
\end{abstract}

JEL Classification: D31

Keywords: early intervention, parenting programme, randomised trial

Corresponding author:

Donal O'Neill

Economics Dept.

NUI Maynooth

Maynooth, Co. Kildare

Ireland

E-mail: donal.oneill@nuim.ie

\footnotetext{
* I would like to thank Sinead McGilloway, Paul Kelly, Olive Sweetman and seminar participants at NUI Maynooth for helpful comments on an earlier draft of this paper.
} 


\section{Introduction}

A number of studies have argued that early childhood factors such as behavioural problems, parental economic status, and family composition, have significant effects on subsequent economic and social success or failure as an adult. To date the majority of the evidence on behavioural problems has been presented in the medical, psychology or sociology literature (e.g. Kazdin (1989), Caspi et al (1998), Miceh et al (1999), Scott et al (2001) and Colman et al (2009)). However more recently economists have begun to give serious consideration to these issues. For example Gregg \& Machin (1999) find that indicators of childhood behavioural problems at age 7 have significant negative effects on school attendance and contact with police (with both outcomes measured at age 16), as well as on the probability of staying on at school after the compulsory school leaving age. This is true even after including a range of additional controls such as measures of cognitive skills and family structure and a broad set of parental characteristics. In their survey of early childhood intervention programs in the U.S. Carneiro and Heckman (2003) note that early interventions can be highly effective in reducing crime, promoting social skills and integrating disadvantaged children into mainstream society, and that some of the most effective interventions operate on non-cognitive, social and emotional skills. ${ }^{1}$

In addition evidence from the psychology literature suggests that parenting variables play an important role in determining early childhood behaviour patterns (Campbell 1995). In keeping with these findings Heckman (2000) argues that early childhood intervention is likely to be the most effective means of overcoming long-run disadvantage. In addition, citing the crucial role of the family in the formation of learning skills, he calls for greater government support at the family level in efforts to tackle long-run inequalities. In this paper we carry out a randomised evaluation of one such early intervention program, The Incredible Years programme, which is designed to prevent and treat behavioural problems in young children. The programme involves a mixture of child, parenting and teacher interventions. In this paper we use the results

\footnotetext{
${ }^{1}$ Other surveys of previous research on early-childhood intervention programs include Barnett (1995), Brooks-Gunn et al (2000) and Currie (2001). Spence-Boocock (1995) discusses results from research conducted outside the United States.
} 
from a randomised experiment to evaluate the impact of the parenting component on measures of early-childhood behaviour in Ireland. As well as detailed behavioural data the study also collected information on service utilisation and costs, which allows us to estimate the cost-effectiveness of the programme. The Irish case is of interest because despite the unprecedented growth experienced in Ireland over the last 10-15 years, Ireland still has one of the highest rates of child-poverty among developed countries (UNICEF 2007). We find that the parenting programme significantly reduced behavioural problems among children, while the cost-benefit analysis carried out in sections 6-7 suggest that the long-run social return from this programme compares favourably to popular alternative policies.

\section{Incredible Years Parenting Programme}

Emotional and behavioural problems often start in early childhood and the need for early intervention has been recognised as a crucial element in reducing the onset of behavioural problems. The Incredible Years Parent, Teacher and Child Training Series was developed, over the last 30 years, at the University of Washington and is specifically designed to prevent and treat emotional and behavioural difficulties in children aged 0-12 years. In this paper we use a randomised experiment to evaluate the basic BASIC Preschool/Early School Years Parent Training programme on children between the ages of 3-8 yrs. This programme aims to improve the skills and parenting strategies of parents, particularly those who find their child's behaviour difficult or challenging. Parent competences are developed in areas such as communication, limitsetting, problem-solving and anger-management. Parents are also encouraged to develop support networks. Two trained facilitators take parents in groups of about 12 and each programme lasts for 12 weeks with a 2 hour session each week. The work covers all the basic aspects of parenting as well as offering help to individual parents who find their child's behaviour challenging. The programme uses a collaborative approach between group leader and parents including analysis of video material of family behaviour for discussion. 


\section{Randomised Trial}

The primary focus of the evaluation in this paper is a multi-site, longitudinal follow-up study incorporating a randomised controlled evaluation of BASIC Preschool/Early School Years Parent Training programme. Randomisation was on the basis of random generated ID numbers assigned by the research team, which allocated participants to either the intervention or control group with a ratio of 2:1. Participants were assessed at baseline in early 2008 (i.e. before they receive the intervention) and then again six months later. The fieldwork during the trial involved the administration of a battery of questionnaires, home and school visits, one-on-one sessions with parents, and the observation of parents and children in the home.

Each parent filled in a profile questionnaire which collected detailed information on family background, employment status and income levels, as well as a service utilisation questionnaire in which parents were asked to record health and social services used by the child and parent over a 6 month period. In addition information was collected on emotional and behavioural problems of the child using a set of clinically approved instruments. The scores on these tests are used to construct the outcome variable of interest in this study.

In total 149 parents were contacted at the intial baseline period, with 139 valid responses. Of this sample 95 (68\%) were randonly assigned to the treatment group and the remaining 44 (32\%) to a control group where treatment was postponed for 6 months. Participants were reinterviewed 6 months later during which time members of the treatment group had particiapted in the parenting programme. Of the 139 individuals chosen at the baseline, valid follow-up data was obatined on 112, of which 74 (66\%) were members of the treatment group and 38 (34\%) were members of the control group.

Summary statistics for the sample of 112 are given in Table 1 . While there is some evidence that parents in the treatment group are more likely to be seperated, live in social housing and have lower incomes, only the difference in the proportion married is statistically significant at the $10 \%$ level. Furthermore these differences do not translate 
into significant pre-intervention differences in the behavioural test scores of the children.

\section{Estimating the Programme Effects}

In order to estimate the cost effectiveness of the Incredible Years programme we first need to obtain the estimated effect of the programme on the children and then combine this with the additional cost of providing this programme. We now provide evidence on both of these components.

\section{4a. Impact of Programme on Child Behaviour.}

In this analysis we use the results from the Eyberg test score as a measure of childhood behavioural problems. The Eyberg test has been developed as a screening instrument for the differentiation of normal and conduct problem children and studies have indicated that the test has good reliability and validity ${ }^{2}$ (Eyberg and Ross (1978) and Eyberg and Robinson (1983)). In total the test considers 36 individual problems, including difficulty following orders, difficulty interacting with other children, problems with attention seeking and problems with concentration and attention span. ${ }^{3}$ For our test score children are assigned a score between one and seven depending on the frequency of the problem ( 1 if the problem never occurs and 7 if the problem always occurs). The final test score is a simple aggregate of the individual scores over the 36 problems. Therefore the maximum score on the test is 252 and the minimum is 36. The clinical cut-off for serious behavioural problems with the Eyberg Test is 127.

Table 2 compares the treatment and control group on the basis of the Eyberg test score. As expected, given the randomised nature of the experiment and our earlier results, column 1 of Table 2 shows no significant differences between the treatment and

\footnotetext{
${ }^{2}$ In psychometrics a reliable measure is one that measures something consistently. A valid measure is one that measures what it is supposed to measure.

${ }^{3}$ Many of the characteristics have been identified by teachers as important determinants of readiness to learn, with teachers placing much less weight on more traditional intellectual achievements (Lewit and Baker 1995, Kiernan et al 2008).
} 
control groups test scores prior to the intervention. However, the treatment group exhibit a significant improvement in their test score 6 months after the intervention, with the score of children who participated approximately $20 \%$ lower than those who did not attend. These findings are similar in magnitude to the results of other international evaluations of the IY programme. For example Edwards et al (2007) report a 27.3 point reduction in mean intensity score. Table 3 reports summary statistics on the change in test score by treatment group. While there were some notably large successes associated with the treatment it is evident from this table that the mean effect identified in Table 2 is not solely driven by outliers. Using the median change in test scores we see that the median drop in test scores was 15 points higher in the treatment than in the control. Furthermore, while over $20 \%$ of the control group experienced a rise in the behavioural index, indicating greater behavioural problems in the follow-up, this was true of less than $10 \%$ of the treatment group. Further evidence of sustained effects throughout the distribution is found in the fact that after the treatment $65 \%$ of the treatment group had Eyberg intensity scores below the clinical cut-off (127), compared to only $36 \%$ of the control group.

Due to the timing of the evaluation the 6 months effects reported above are the longest for which we have data currently available. While we know of no long-run evaluation of the Incredible Years programme, the evidence available does suggest that the initial gains we identify here may have a significant long-run component. Hutchings et al (2004) report on a four-year follow up evaluation of a structured parenting programme similar in many ways to the Incredible Years programme. They found that the substantial improvements in child behaviour observed after the 6 month follow-up were still evident four years after the intervention had stopped. This was in contrast to a control group who received a less intensive programme but exhibited no evidence of long-run gains. ${ }^{4}$

\footnotetext{
${ }^{4}$ In addition Webster-Stratton, Rinaldi and Reid (2009) carried out assessments of participants 8-12 years after contact with the programme. Although no control group is available in this case, the results suggest that the treated children showed less severe indications of conduct problems at adolescence (e.g. limited contact with the criminal justice system) than might have been expected given their earlier clinical levels of conduct disorder.
} 


\section{4.b Service Usage}

A Service Utilisation Questionnaire (SUQ) was used to assess the frequency and costs of health, social and educational services used by children in the intervention and control arms of the parent training trial. The SUQ yields information pertaining to child health, contact with health services, school services, hospital visits etc. It also contains questions about the main carer's health and their contact with health services

Data on service utilisation are obtained for the previous six months. A period of six months is deemed to be sufficient in order to obtain a representative picture of service usage, whilst also being sufficiently recent to allow the respondent to recall accurately the frequency and nature of contacts.

This questionnaire is administered by face-to-face interview with the main caregiver who is asked questions about the child's use of a wide range of health and social services and special educational services including GP, nurse, health visitor, speech therapist, social worker, educational psychologist and hospital visits (outpatient, A\&E and/or inpatient) and attendance at a special school. Respondents are also asked to report the location of the contact such as a GP surgery, the home, health clinic or school/nursery. Other services (or locations) not specifically included in the questionnaire may also be noted. The questionnaire also asks the main carer to report the type and frequency of their own contacts with a range of health care services (e.g GP, nurse, social worker, counsellor etc.) during the previous six months. There is considerable evidence in the literature of the links between child behaviour and maternal health. The SUQ was administered at two time points: at baseline , before parent/caregivers begin the parenting course and 6 and (in the case of the intervention group) 12 months after baseline.

The details on service use are given in Table 4. Looking at the results we see that in terms of primary care the services most availed of were GP's, Nurses and Speech Therapists. ${ }^{5}$ The remaining primary care services such as social workers, paediatricians, and physiotherapists tended to be used by less than $10 \%$ of either

\footnotetext{
${ }^{5}$ Comparisons to the general population are difficult given the time span involved though Madden, Nolan and Nolan (2005) report that the proportion of the total adult population in Ireland who had visited a GP at least once in the previous 12 months rose from $70.9 \%$ in 1987 to 85.6 in 2000 for medical card holders and from 52.9 to 66.9 for non-medical card holders (see Table 2 of their paper). Harmon and Nolan (2001) report that $16.7 \%$ of the adult population had an outpatient visit to a hospital during 2000 (see Table 3 of their paper). The comparative figures for in-patient and A\&E visits were $12.9 \%$ and $11.8 \%$ respectively.
} 
sample. In terms of special resources during schooling only one-to-one help, which is likely to mean accessing Special Needs Assistants, was a significant service.

Of additional interest is the comparison of service use before and after the intervention. While there is some evidence of a fall in service use by the control group, particularly in the area of speech therapy, the decline in service use over time is more prevalent in the treatment group. In particular we see substantial falls in many of the primary care services, as well as a reduction in the services of social workers. By the end of the sample only $1 \%$ of the treatment group reported having visited a social worker in the previous 6 months. This fall in service use is consistent with the improvement in child behaviour noted earlier and will enhance the cost-effectiveness of the program.

\section{Cost Data.}

\subsection{Unit-Service cost}

To estimate the cost-effectiveness of the programme we need to be able to cost these services. In previous studies, much of the unit cost data were publicly available; for example, Edwards et al (2007), in their UK-based study, used the Unit Costs of Health and Social Care annual publication. There is no comparable publication for Ireland. Table 5 lists the key services as identified in the data provided by the Service Utilisation Questionnaire and the unit costs data collected for these services. For some categories (e.g GP visits), the costs are well-established. For some of the others (e.g. A\&E, Outpatient and Overnight stay in paediatric hospital) costs were obtained from the Casemix/HIPE unit of the Health Service Executive. ${ }^{6}$ The Casemix unit of the HSE was developed to collect data on the activity and costs of hospitals in Ireland. Each hospitals mix of cases is categorised into Diagnoses Related Groups (DRG's) which share common clinical attributes and simialr patterns of resource use (e.g hip replacement, coronary bypass, burns...). Cost are derived from the annual accounts of the hosptials

\footnotetext{
${ }^{6}$ I am grateful to Fiachra Bane, CASEMIX/HIPE analyst at the HSE for providing these figures. More information on the Irish Casemix system can be found at http://www.casemix.ie/.
} 
under headings such as salaries, radiology, labs, drugs and then allocated to the 665 DRG's, giving an average cost per case.

\subsection{Cost-Diaries}

The final component of the costs for the Incredible Years Program is the direct costs per child of running the program over the 14 week period. These costs were obtained from cost-diaries that each of the instructors was required to fill in for each week of the program. Instructors were asked to record time spent each week on actual session time and home visits/telephone calls, as well as travel costs incurred. In addition some instructors received additional expenses for Childminding facilities, food, hall rentals and stationary. A total of 18 cost diaries were completed and costs are summarized in Table 6. Direct wage costs were the dominant cost associated with the programme, accounting for almost $90 \%$ of total costs. Additional expenses accounted for the majority of the remaining costs, with travel expenses being a minor component of overall costs. The average total cost per duration of the programme across the 9 groups was €16102. Working on an assumed average group size of 11 parents/children per group, this implies an average total cost per client of $€ 1463$. This is the direct training cost figure used in the cost-evaluation.

Table 7 combines our service usage data and our leader cost data to estimate the incremental costs associated with the Incredible Years Programme. The final row indicates that the additional net cost of the programme was approximately $€ 1520$. This estimate is used in the next section to construct an estimate of the cost-effectiveness of the programme.

\section{Cost-Effectiveness of Incredible Years Parenting Program}

A traditional approach to studying cost-effectiveness in the health evaluation literature is to define cost-effectiveness in terms of the incremental cost effectiveness ratio (ICER) of the new treatment $(\mathrm{T})$ relative to specified alternative (most commonly 
chosen to be the status quo). Examples of the use of ICERs include Raikou et al. (1998) who examine the economic efficiency of tight blood pressure control in hypertensive patients with type 2 diabetes and the UK alcohol treatment trial (UKATT) research Team (2005) who examined the cost-effectiveness of social behaviour and network therapy for people with alcohol problems. More recently Edwards et al (2007) examined the costeffectiveness of the Incredible Years program in Wales.

Formally the ICER is defined as:

$$
R=\frac{\left(C_{T}-C_{C}\right)}{\left(E_{T}-E_{C}\right)}
$$

where $C_{T}$ and $C_{C}$ are the population mean cost of the treatment $(T)$ and the control (respectively) and $\mathrm{E}_{\mathrm{T}}$ and $\mathrm{Ec}$ measure the population mean health effect associated with the treatment and control groups. The ratio of the incremental cost to the incremental benefit can be interpreted as the additional investment of resources required for each additional unit of health improvement expected from investing in treatment $\mathrm{T}$ rather than in treatment $\mathrm{C}$.

This is estimated from the data using an analogue estimator:

$$
\hat{R}=\frac{\left(\overline{C_{T}}-\overline{C_{C}}\right)}{\left(\overline{E_{T}}-\overline{E_{C}}\right)}
$$

where $\overline{C_{j}}$ is the sample average cost incurred by members of group $\mathrm{j}$ (j=treatment $(\mathrm{T})$, control (C)) and $\overline{E_{j}}$ is the sample average of the outcome variable for group $\mathrm{j}$ (in our case the Eyberg Intensity Score). As defined, the ICER simply measures the cost of obtaining a one unit decrease in the Eyberg score when using treatment $\mathrm{T}$ when compared 
to treatment $\mathrm{C}$. The extent to which the program can be viewed as cost-effective will depend on society's preferences and this will be discussed in more detail later. ${ }^{7}$

Combining results from Tables 2 and 7, we estimate a cost-effectiveness ratio of $€ 72$ per 1 point change in the Eyberg intensity score (1520/21; where the numerator is the difference in difference estimate of the cost change and the denominator is the difference in difference estimate of the change in test score brought about by the treatment). This estimate compares to the point estimate of $£ 73$ (€83) obtained by Edwards et al (2007) in their study of the IY program in Wales. Our point estimate implies that it would cost $€ 7848$ ((235-126)*72) to bring the child with the highest intensity score to below the clinical cut-off point and $€ 2232$ ((157-126)*72) to bring the average child in the study below this limit. $^{8}$ We will discuss these estimates in the context of a full cost-benefit analysis in Section 7.

Before doing so a number of researchers in the areas of health economics evaluation have called for this fundamental cost-effectiveness measure to be complemented using Probabilistic Sensitivity Analysis (PSA) (e.g van Hout et al (1994)). Confidence intervals for our point estimate can be constructed either parametrically, if one is willing to make distributional assumptions, or non-parametrically (e.g using bootstrap) if a closed form expression for the distribution of the estimator is difficult to obtain. A 1000 replication bootstrap of our data yielded a mean estimate of $€ 78$ (90\% CI €33 to €147).

Some additional insight into the interpretation of our estimates can be obtained by carrying out a range of hypothesis tests. In particular we consider tests of the following form:

$$
H_{o}: \frac{\left(C_{T}-C_{C}\right)}{\left(E_{T}-E_{C}\right)} \geq k \text { versus } H_{A}: \frac{\left(C_{T}-C_{C}\right)}{\left(E_{T}-E_{C}\right)}<k
$$

\footnotetext{
${ }^{7}$ Stinnett and Mullahy (1998) have identified a number of problems with the use of ICER for this type of sensitivity analysis and have turned to the related concept of the Incremental Net Health Benefit Statistic (INHBS). However both the ICER and INHB statistics will lead to the same results in the event that both the incremental costs and incremental benefits are positive, which, as we will see, turns out to be the case for our application (see also Briggs and Fenn (1998)).

${ }^{8}$ The mean Eyberg score is based on the full sample of children.
} 
As posed, the hypothesis asks us to consider the conjecture that our programme can be deemed cost effective relative to a benchmark value €k. Rejecting the nullhypothesis in favour of the alternative, is strong-evidence that our programme is costeffective for the given $k$. In this sense ' $k$ ' can thought of as measuring the maximum price society is willing to pay for an incremental gain in health. As usual in econometrics we might considering reporting the p-value associated with this hypothesis. ${ }^{9}$ Let us call this p-value, $\mathrm{p}_{\mathrm{k}}$, where the p-value is indexed by $\mathrm{k}$ to remind us that the hypothesis is specified for a given value of $\mathrm{k}$. It is typical in classical econometrics to require p-values smaller than at least .1 before considering rejecting a null-hypothesis. ${ }^{10}$ That is, if $\mathrm{p}_{\mathrm{k}}<.1$ we can 'confidently', with at most a $10 \%$ chance of being wrong, reject the nullhypothesis and thus deem our programme to be cost-effective against a willingness to pay of $€ \mathrm{k}$

One problem with the approach as outlined above is that it is conditional on a given k. However, we are unlikely to know society's willingness to pay. In addition it may vary over time and place and indeed across governments entrusted with funding potential programmes. One solution to this is to repeat the above analysis for a range of $k$, thereby allowing individuals/policy-makers to assess how support for cost-effectiveness varies across these prices. Graphically, one might consider plotting $\mathrm{p}_{\mathrm{k}}$ against $\mathrm{k}$, for range of $\mathrm{k}$. In fact it is more common to plot $\left(1-\mathrm{p}_{\mathrm{k}}\right)$ against $\mathrm{k} .^{11}$ In the health economics literature the resulting curve is known as the Cost-Effectiveness Acceptability Curve (CEA curve). Clearly an increase in $\mathrm{k}$ raises the possibility of our programme being deemed cost-effective and hence our confidence level should increase ( $\mathrm{p}$-value decline). ${ }^{12}$ However, the exact shape of the curve is unknown without considering the data in detail.

The CEA curve for our application is given in figures 1 . Given uncertainty about the parametric distribution of the ICER, we use a 1000 replication bootstrap to estimate

\footnotetext{
${ }^{9}$ This is simply the minimum significance level at which our null-hypothesis would be rejected given the data.

${ }^{10}$ See Briggs (1994) for a more detailed discussion of the Bayesian and Classical approaches to probability in this context. Here we adopt the traditional classical interpretation.

${ }^{11}$ Given the relationship between hypothesis testing and confidence levels (1-p) is the one sided confidence level at which the ICER is just significantly different from $\mathrm{k}$ (see Lothgren and Zethraeus (2000)).

${ }^{12}$ However, see Fenwick et al (200) for examples of data generating processes that do not exhibit this behaviour. However, these examples require that a non-negligible proportion of the joint density of incremental costs and effects straddle multiple quadrants in the incremental cost-benefit plane. Analysis of our data suggests that that this is not the case with our application.
} 
the associated p-values for each level of k. Following our earlier discussion we distinguish between $\mathrm{k}$-values for which $\mathrm{p}_{\mathrm{k}}>.1$ and those for which $\mathrm{p}_{\mathrm{k}}<.1$. From our graph we can then infer that we are $90 \%$ confident that the Incredible Years programme would be cost-effective, provided society was willing to pay at least $€ 120$ for a one-point reduction in the problem test-score. Alternatively with $90 \%$ confidence we propose that a 1 unit improvement in Eyberg score can be obtained for at most $€ 120$.

\section{Cost-Benefit Implications}

To date there have been relatively few cost-benefit analysis of early intervention programs of the type considered in this paper. Aos et al (2004) undertake a series of cost-benefit analysis for a range of early intervention programmes. Looking at their results for Pre-Kindergarten Education Programmes and Home-Visitation Programmes, they find that while some programs (such as early child education for low income families, Nurse-Family Partnership for Low income Women, and Home Visitation Programs for at Risk Mothers and children) achieve significantly higher benefits than costs, others (such as Early Head Start, Comprehensive child Development programme and Infant Health and Development Programme) were less successful in this respect, yielding net losses of between $\$ 16203$ and $\$ 49000$ per youth. The unsuccessful programmes were all characterised by extremely high costs (ranging from \$20000 to $\$ 49000$ per youth), reflecting in some cases, such as Early Head Start, the much more intensive nature of the intervention ${ }^{13}$ As noted earlier the estimated cost per youth of the IY programmes is a much more modest $€ 1463$ per youth. While many of the programs discussed by Aos et al (2004) have features in common with the Incredible Years program, this program itself was not included on the grounds that the outcomes associated with the program (reductions in child conduct disorder) are difficult to value. While we accept that this is the case we nevertheless feel that there is some merit in trying to put the cost-effectiveness analysis provided in the previous section in context.

\footnotetext{
${ }^{13}$ In addition the low return to Early Head start reported by Aos et al (2004) reflects a very restrictive view of the likely benefits of the program. In particular the only benefit attributed to Early Head Start is its effect on cognitive test scores. This seems to be a rather pessimistic reading of the evidence presented in Love et al (2004).
} 
To do this we look at studies that have tried to relate improvements in conduct disorder to outcomes which are relatively easy to value.

\subsection{Conduct Disorder and Crime}

Scott et al (2001) use a longitudinal sample of children from Inner City London to follow children from age 10 to age 28. Children were screened in the initial wave and on the basis of this clinical screenings were categorised into three groupings; those with no behavioural problems, those with mild behavioural problems and those with severe conduct disorder. Detailed life-history data, including educational history, pyschological functioning, work and marital status, educational provision and criminal records were obtained during follow-up surveys. They estimate that those with conduct disorder were 3 times more likely to have been convicted of a crime than those with no problems and 12 times more likely to have spent time in prison. ${ }^{14}$ Using data collected during the course of a 25 year longitudinal study of a birth cohort in New Zealand Fergusson et al (2005) report that children diagnosed with severe conduct problems at age 7-9 were 5 times more likely to be arrested at ages 21-25 than those with less severe problems and almost 20 time more likely to have been imprisoned, even after controlling for a wide range of additional early family and child characteristics. In an Irish context Cleary et al (2004) conducted a 10 year longitudinal study of young children and found that $47 \%$ of those with behavioural problems in childhood were subquently in trouble with the police compared to only $14 \%$ of the non-deviant group.

\subsection{Conduct Disorder and Unemployment}

Caspi et al (1998) find that adolescents with conduct disorder are likely to be unemployed for 5 months longer during the ages of 21-26 than those without, over half of which is explained by shorter education spells and higher levels of substance abuse. In addition Scott et al (2001) reported that welfare payments until the age of 28 were 1.65 times higher for children with problems than for those with none. While, Colman et al (2009) report no significant differences across behavioural groups in

\footnotetext{
${ }^{14}$ This latter comparison is based on relatively small numbers.
} 
unemployment, their definition of unemployment was relatively weak. ${ }^{15}$ However, they do report that individuals with severe behavioural problems were almost twice as likely to report experiencing financial difficulties in adulthood.

\subsection{Conduct Disorder and Education}

Miech et al (1999) show that children with conduct disorder are 5 times less likely to earn a School Certificate (state exam at age of 16 in New Zealand) than those without behavioural problems. Of those who did earn the certificate those with a conduct disorder were 3.3 times less likely to complete high school, and conditional on doing so were 2.5 times less likely to go to university. Colman et al (2009) found that children with severe behavioural problems in the UK were more than twice as likely to leave school without a recognised educational qualification than those with no behavioural problems, and that this effect remained significant even when controlling for family socioeconomic background and other child characteristics. In addition Scott et al (2001) found that children with conduct problems were much more likely to need remedial help at primary and secondary school, require the intervention of a social worker for truancy cases and require literacy classes when older. Fergusson et al (2005) found that children with severe behavioural problems were 10 times more likely leave school with no educational or vocational qualification that those no severe behavioural problems. However, in contrast to the findings for Colman et al (2009) in the UK, this difference was not statistically significant once a range of family and child characteristics were controlled for. In their Irish study Cleary et al (2004) found that sixty-six percent of the behaviourally deviant group left secondary school before completing the Leaving Certificate compared with only 19\% in the non-deviant group. Furthremore participation in third level also varied considerably. Approximately fifty percent (51\%) of the nondeviant group went to third level education but only $16 \%$ of the group classified as behaviourally deviant

\footnotetext{
${ }^{15}$ In particular they only consider whether an individual had ever experienced a spell of unemployment and do not adjust for differences in duration or multiple spells of unemployment.
} 


\subsection{Cost-Benefit Analysis of Incredible Years Programme}

In this section we combine the results from these studies with our evaluation of the Incredible Years programme to estimate the potential long-run returns of the Incredible Years program. We consider potential benefits under each of the three categories discussed above.

The latest figures for Ireland suggest that the average cost of keeping a prisoner during the calendar year 2007 was $€ 97700 .^{16}$ Fergusson et al (2005) estimated that the gap in the probability of imprisonment between those with behavioural problems and those without was 7 percentage points. Using this figure gives an approximate measure of the additional cost of prison arising from conduct disorder in the order of $€ 6839$ per person.

In addition we might consider including as an additional source of societal benefit a reduction in unemployment duration of the order of 5 months, as mentioned by Caspi et al (1998). It is estimated that the annual cost of unemployment in Ireland in terms of welfare payments and losses in taxes is approximately €15000, which when combined with Caspi et al's estimate leads to an expected savings of €6250. Again assuming for simplicity that this is a once off savings occurring again at the age of 30 , In our calculations we assume that the savings from reduced criminal activity occur only once and at the age of $30 .{ }^{17}$

Finally, as noted above a number of authors have pointed out the potential educational benefits arising from reduced behavioural problems, including less reliance on remedial education (Scott et al 2001) and increased graduation rates at both second and third level (Colman et al 2009)). In an attempt to capture some of the societal benefits to the state we consider one hour a week less contact with special needs assistance for each of the first 4 years of primary school. Given a school year of 37 weeks and an hourly pay rate of $€ 15.20$ for Special Needs Assistants, this translates into an annual savings of $€ 562.40$ for each of the 4 years of schooling.

From our earlier analysis we know that mean Eyberg score pre-intervention was 157. To reduce this score below the critical level requires a 31 point decrease. Costing

\footnotetext{
${ }^{16}$ Irish Prison Service Annual Report (2007).

${ }^{17}$ This is the average age of the prison population in Ireland in 2007 (Irish Prison Service Annual Report 2007).
} 
each point reduction using our estimate of $€ 72$ gives a mean cost of bringing the median problem child below the clinical cut-off value of $€ 2232$.

Given all these assumptions we can estimate the internal rate of return of the programme as the interest rate that solves the following problem:

$$
\left(\sum_{t=1}^{4} \frac{562}{(1+r)^{t}}\right)+\frac{6839+6250}{(1+r)^{25}}-2232=0
$$

This leads us to an internal rate of return of $13.3 \% .^{18}$

As a robustness check we could take a rather extreme assumption and assume that the reduction in crime is the only benefit arising from treatment of conduct disorder. ${ }^{19}$

In this case the is given as the solution to

$$
\frac{6839}{(1+r)^{25}}-2232=0
$$

resulting in an estimated return of $4.6 \%$.

These estimates are intended to be illustrative of the potential return associated with the parenting programme under evaluation. Other benefits such as improvements in second and third level educational attainment and the associated increases in productivity and earnings capacity, reductions in substance abuse, benefits to victims of reduced crime and benefits accruing to the parents as a result of the programme are likely to push these returns higher. On the other hand the short-run nature of our evaluation leaves open the question as to whether additional programme costs may be needed in the future so as to maintain the short-run benefits identified in our evaluation.

\footnotetext{
${ }^{18}$ Some commentators prefer to summarise investments using Net Present Values rather than internal rate of returns, especially when initial outlays may vary across investments. Assuming an opportunity cost of capital of $5 \%$ the NPV of the Incredible Years programme given our assumptions is $€ 4599$ per child.

${ }_{19}$ The savings in criminal costs are by far the largest components of the estimated additional costs associated with conduct disorder in the UK as reported by Scott et al (2001) and also the largest component of the estimated benefits associated with pre-school intervention programmes as estimated by Barnett (1996).
} 
However, the results reported by Hutchings et al (2004), and discussed earlier in section 4 , are encouraging in this respect. Therefore on the basis of the evidence available it would seem plausible that the estimated rates of returns presented above may if anything underestimate the true rate of return. In spite of this, these estimates compare favourably with previous evaluations of policies aimed at tacking disadvantage. For example the estimated internal rate of return of the Perry Preschool Project, perhaps the most heralded early childhood intervention programme in the United States, was 8\% (Barnett 1992)), while many of the adult training programmes studied surveyed by Heckman et al (1999) yielded negative returns. Our cost-benefit analysis therefore suggests that parenting programmes such as the Incredible Years programme may be a cost-effective policy in reducing long-term inequalities.

\section{Conclusions}

The call for an increased policy focus on early childhood interventions and in particular policies that tackle the role of the family in early childhood development has been growing in recent years. This call is based on the dual premise that 'skill begets skill’, so that early childhood intervention can result in cumulative gains over the life-cycle, and that the family environment plays a significant source of early childhood disadvantage. This paper uses a randomised controlled experiment to evaluate the impact of one such early childhood intervention programme aimed at improving the the ability of parents to deal with children exhibiting extreme forms of behavioural problems. Our analysis shows that the treatment significantly reduced behavioural problems in young children when measured 6 months after the intervention. Furthermore our cost-benefit analysis suggest that the long-run rate of return from programmes such as these are likely to be compare favourably with more intensive alternative policies. 
Table 1: Summary Statistics

\begin{tabular}{|l|l|l|l|}
\hline & Treatment Group & Control Group & $\begin{array}{l}\text { p-value for Equality } \\
\text { across Treatment groups }\end{array}$ \\
\hline Male Child & .58 & .68 & .288 \\
\hline Parent’s Gender & .97 & .97 & .98 \\
\hline Parent's Age & 34 & 35 & .59 \\
\hline Married & .31 & .50 & .07 \\
\hline Seperated/Divorced & .11 & .03 & .13 \\
\hline Single & .24 & .24 & .94 \\
\hline Social Housing & .40 & .37 & .81 \\
\hline Employed & .23 & .24 & .93 \\
\hline Weekly Income $<€ 300$ & .47 & .32 & .11 \\
\hline White & .93 & .84 & .13 \\
\hline Eyberg Intensity Score & 157 & 161 & .54 \\
\hline
\end{tabular}

Table 2: Treatment Effect of Intervention (Standard Errors in Parentheses)

\begin{tabular}{|l|l|l|}
\hline Variable & Baseline & Follow-up \\
\hline Treatment & -7.67 & $-29.2^{* *}$ \\
Indicator & $(6.7)$ & $(7.9)$ \\
\hline Constant & 180.74 & 134.87 \\
& $(19.45)$ & $(22.9)$ \\
\hline $\mathrm{N}$ & 112 & 112 \\
\hline Other Controls & Yes & Yes \\
\hline
\end{tabular}


Table 3: Distribution of Treatment Effect of Intervention

\begin{tabular}{|c|c|c|c|}
\hline $\begin{array}{l}\text { Dependent Variable }- \text { Fall } \\
\text { in Eyberg Score post } \\
\text { intervention }\end{array}$ & Control & Treatment & $\begin{array}{ll}\text { p-value } & \text { for } \\
\text { difference }^{*}\end{array}$ \\
\hline $10 \%$ tile & -48 & -87 & .022 \\
\hline $25 \%$ tile & -31 & -64 & .002 \\
\hline Median & -21 & -36 & .067 \\
\hline 75\%tile & -4 & -13 & .228 \\
\hline $90 \%$ tile & +10 & 0 & .513 \\
\hline Maximum Change & -53 & -128 & \\
\hline Minimum Change & +22 & 40 & \\
\hline $\begin{array}{l}\text { Proportion for whom test } \\
\text { score increased }\end{array}$ & $23.68 \%$ & $9.46 \%$ & \\
\hline
\end{tabular}

Table 4: Proportion using Medical Services at Baseline and Follow-up survey

\begin{tabular}{|l|l|l|l|l|}
\hline Service & $\begin{array}{l}\text { Control } \\
\text { Baseline }\end{array}$ & $\begin{array}{l}\text { Treatment } \\
\text { Baseline }\end{array}$ & $\begin{array}{l}\text { Control } \\
\text { Follow-up }\end{array}$ & $\begin{array}{l}\text { Treatment } \\
\text { Follow-up }\end{array}$ \\
\hline GP & $53 \%$ & $64 \%$ & $55 \%$ & $42 \%$ \\
\hline NURSE & $13 \%$ & $10 \%$ & $5 \%$ & $5 \%$ \\
\hline Health Visitor & $8 \%$ & $12 \%$ & $5 \%$ & $3 \%$ \\
\hline $\begin{array}{l}\text { Speech } \\
\text { Therapist }\end{array}$ & $21 \%$ & $21 \%$ & $8 \%$ & $5 \%$ \\
\hline Physiotherapist & $3 \%$ & $8 \%$ & $5 \%$ & $3 \%$ \\
\hline Social Worker & $5 \%$ & $9 \%$ & $10 \%$ & $1 \%$ \\
\hline $\begin{array}{l}\text { Community } \\
\text { Paediatrician }\end{array}$ & $3 \%$ & $5 \%$ & $0 \%$ & $1 \%$ \\
\hline $\begin{array}{l}\text { Special Needs } \\
\text { Assistant }\end{array}$ & $18 \%$ & $12 \%$ & $13 \%$ & $12 \%$ \\
\hline $\begin{array}{l}\text { A\&E } \\
\text { Department }\end{array}$ & $8 \%$ & $12 \%$ & $10 \%$ & $12 \%$ \\
\hline $\begin{array}{l}\text { Outpatient stay } \\
\text { in hospital }\end{array}$ & $10 \%$ & $20 \%$ & $11 \%$ & $10 \%$ \\
\hline $\begin{array}{l}\text { Overnight Stay } \\
\text { in hospital }\end{array}$ & $2 \%$ & $5 \%$ & $3 \%$ & $7 \%$ \\
\hline
\end{tabular}


Table 5: Unit Costs Data obtained to date, for the Incredible Years Ireland Study

\begin{tabular}{|c|c|}
\hline GP & $€ 45$ \\
\hline Nurse & $\begin{array}{l}€ 24 \text { an hour (Estimate based on Dept. of } \\
\text { Health \& Children Payscales for Public } \\
\text { Health Nurse) }\end{array}$ \\
\hline Health Visitor & NOT USED \\
\hline Speech Therapist & $\begin{array}{l}€ 22.11 \text { an hour (Estimate based on Dept. of } \\
\text { Health \& Children Payscales) }\end{array}$ \\
\hline Physiotherapist & $\begin{array}{l}€ 22.11 \text { an hour (Estimate based on Dept. of } \\
\text { Health \& Children Payscales) }\end{array}$ \\
\hline Social Worker & $\begin{array}{l}€ 19.23 \text { an hour (Estimate based on Dept. of } \\
\text { Health \& Children Payscales for Social Care } \\
\text { worker) }\end{array}$ \\
\hline Community Paediatrician & $€ 24$ \\
\hline $\begin{array}{l}\text { In-School Assistance } \\
\text { Special Teaching }\end{array}$ & $\begin{array}{l}€ 15.20 \text { an hour (Estimate based on Dept. of } \\
\text { Education Payscales for SNA) }\end{array}$ \\
\hline \multicolumn{2}{|l|}{ Hospital } \\
\hline Casualty Department (A\&E) & $\begin{array}{l}€ 273 \text { (Dept. of Health Casemix/HIPE Unit - } \\
\text { direct correspondence) }\end{array}$ \\
\hline Travel by ambulance & $€ 83$ (Gannon et al) \\
\hline Outpatient Consultant appointment & $\begin{array}{l}€ 160 \text { (Dept. of Health Casemix/HIPE Unit - } \\
\text { direct correspondence) }\end{array}$ \\
\hline Overnight & $\begin{array}{l}\text { €1562 (Dept. of Health Casemix/HIPE Unit - } \\
\text { direct correspondence) }\end{array}$ \\
\hline
\end{tabular}


Table 6: Program costs Leader Cost Diaries

\begin{tabular}{|c|c|c|c|}
\hline & $\begin{array}{c}\text { Total Cost of } \\
\text { Programme }\end{array}$ & $\begin{array}{c}\text { Average Cost per } \\
\text { Group }\end{array}$ & $\begin{array}{c}\text { Average Cost per } \\
\text { client }\end{array}$ \\
\hline & $€ 128321$ & $€ 14257$ & $€ 1296$ \\
\hline Direct Wage Costs & $€ 15219$ & $€ 1691$ & $€ 153$ \\
\hline $\begin{array}{c}\text { Expenses other than } \\
\text { Hours and Mileage }\end{array}$ & $€ 1389.5$ & $€ 154$ & $€ 14$ \\
\hline & & & $€ 1463$ \\
\hline
\end{tabular}


Table 7: Health Social Care and Special Education Services used by Children. Figures are mean total cost per child (€).

\begin{tabular}{|c|c|c|c|c|}
\hline \multirow[t]{2}{*}{ Type of Service } & \multicolumn{2}{|c|}{ At Baseline } & \multicolumn{2}{|c|}{ At 6 month follow up } \\
\hline & Control & Treatment & Control & Treatment \\
\hline Primary Care & 112.43 & 150.93 & 107.6 & 98.7 \\
\hline Hospital Services & 152.02 & 405.58 & 195.57 & 196.97 \\
\hline Special Education & 826.8 & 556.75 & 450 & 560.5 \\
\hline Social Services & 3.03 & 4.93 & 21.25 & 0 \\
\hline Parenting Programme & None & None & None & 1463 \\
\hline Total & 1094.28 & 1118.09 & 774.42 & 2319 \\
\hline $\begin{array}{l}\text { Change in cost over } 6 \\
\text { months }\end{array}$ & & & -319.86 & 1201 \\
\hline Net Change in Cost & & & & $1201+319.86=1520$ \\
\hline
\end{tabular}


Cost-Effectiveness Acceptability curve for IY Evaluation

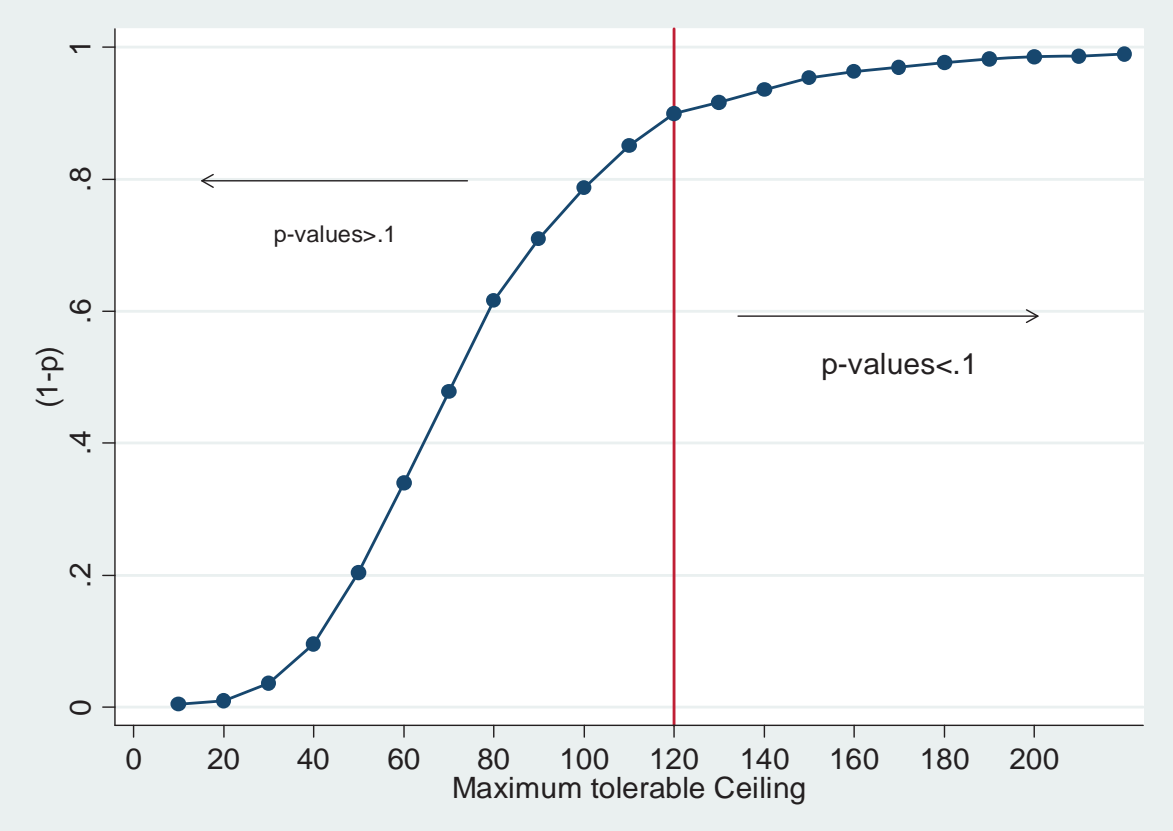


Figure 1: Cost-Effectiveness plane for Incredible Years Evaluation

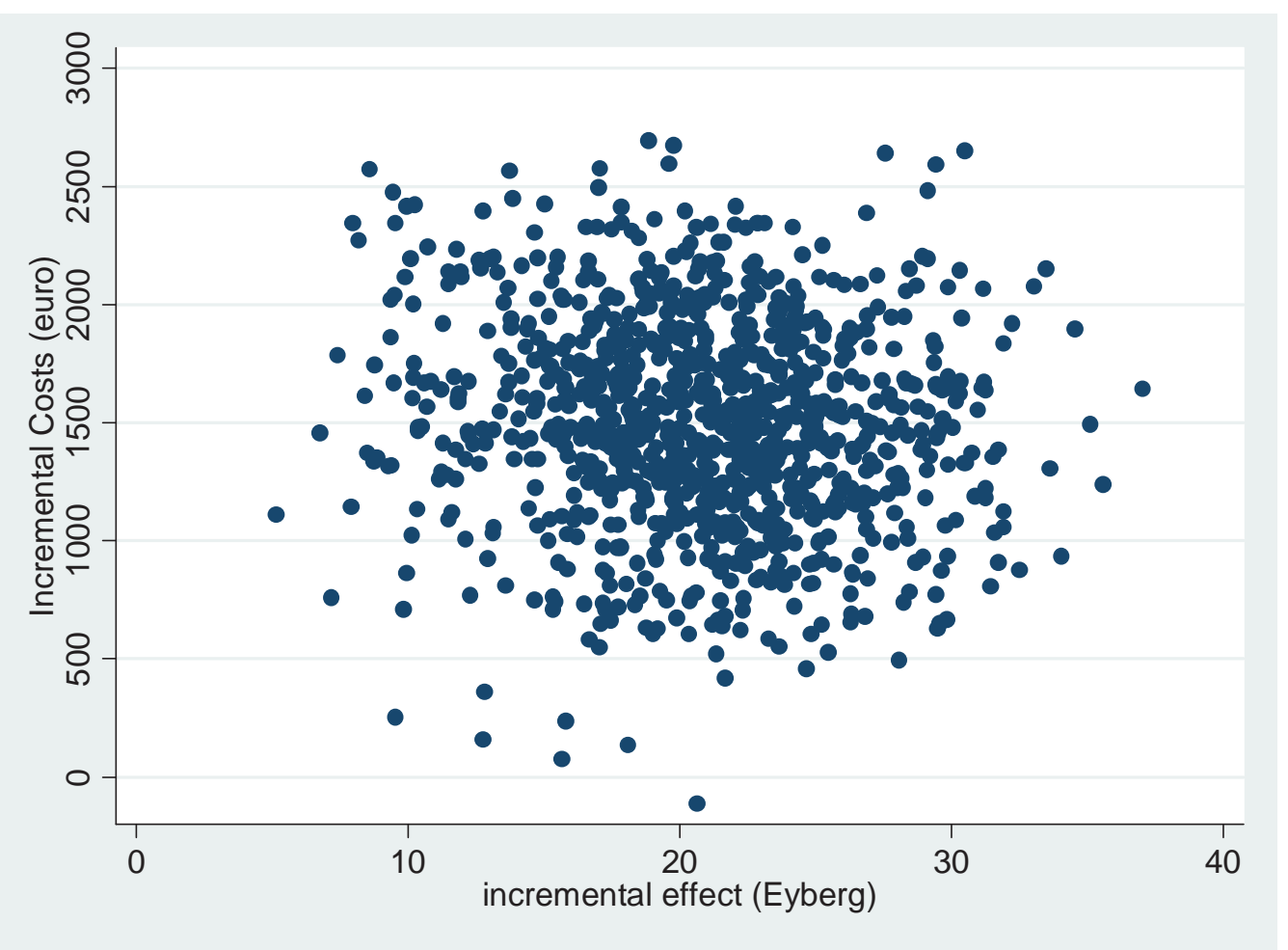




\section{References}

Aos, A, R. Lieb, J. Mayfield, M. Miller and P. Pennucci (2004) "Benefits and Costs of Prevention and Early intervention Programs for Youth,” Olympia, Washington State Institute for Public Policy. Available at http://www.wsipp.wa.gov/rptfiles/04-73901.pdf

Barnett, S (1992) "Benefits of Compensatory Preschool Education," The Journal of Human Resources, Vol. 27(2), pp. 279-312.

Barnett, S. (1995), "Long-Term Effects of Early Childhood Programs on cognitive and School Outcomes," The Future of Children, 5(3), pp. 25-50.

Barnett, S. (1996), "Lives in the Balance: Age 27 Benefit Cost Analysis of the High/Scope Perry Preschool Program. High/Scope Educational Research Foundation Monograph no. 11, Ypsilanti, Michigan.

Benasich, A., J. Brooks-Gunn and B. Clewell (1992) "How do Mothers Benefit from Early Intervention Programs?” Journal of Applied Developmental Psychology, 13, pp. 311-62.

Boocock, S. (1995), "Early Childhood Programs in Other Nations: Goals and Outcomes,” The Future of Children, 5(3), 94-114.

Briggs, A. and P. Fenn (1998), "Confidence Intervals or Surfaces? Uncertainty on the Cost-Effectiveness Plane,” Health Economics, 7, pp. 723-740.

Briggs, A. (1999) “A Bayesian Approach to Stochastic Cost-Effectiveness Analysis,” Health Economics, 8, 257-261.

Brooks-Gunn, J., L. Berlin and A. Fuligni (2000) "Early childhood Intervention Programs: what about the Family?" Handbook of Early Childhood Intervention, $2^{\text {nd }}$ Edition, J.P. Shonkoff and S. Meisels (eds), New York, Cambridge University Press.

Brophy, J. and L. Joseph (1995), "Placing Trials in context using Bayesian analysis. GUSTO revisited by Reverend Bayes, Journal of the American Medical Association. 273, pp. 871-875.

Campbell, S (1995) "Behaviour Problems in pre-school children: A Review of recent research,” Journal of Child Psychology and Psychiatry, 36, pp. 113-149.

Careniro, P. and J. Heckman (2003), "Human Capital Policy,” in Inequality in America, eds. J. Heckman and A. Krueger, MIT Press. 
Caspi, A, B. Enter Wright, T. Moffitt and P. Silva (1998) "Early Failure in the Labor Market: Childhood and Adolescent Predictors of unemployment in the Transition to Adulthood,” American Sociological Review, Vol. 63, no. 3, pp. 424-451.

Chuddar, M. and Stearns S (1996) "Estimating Confidence intervals for CostEffectiveness Ratios, an example from a randomized trial," Statistics in Medicine, 15, 1447-1458.

Colman, I, J. Murray, R. Abbott, B. Maughan, D. Kuh, T. Croudace and P. Jones (2009), "Outcomes of Conduct Problems in Adolescence: 40 Year follow-up of National Cohort,” British Medical Journal, 2009: 338a:2981.

Cleary, A. Fitzgerald, M \& Nixon, E. (2004). "From Child to adult: A longitudinal study of Irish children and their families," available online at

Currie, J (2001) "Early Childhood Education Programmes," Journal of Economic Perspectives, Vol. 15(2) pp. 213-238.

Edwards, R, O’Ceilleachair, A. Bywater, T, Hughes, D. and Hutchings, J. (2007) "Parenting programme for parents of children at risk of developing conduct disorder: cost effectiveness analysis,” British Medical Journal, 2207: 335:682.

Eyberg. S and A. R (1978), “ Assessment of child Behavior Problems: The Validation of a New Inventory,” Journal of clinical child Psychology, Summer, pp. 113-116.

Eyberg, S. and E. Robinson (1983), "Conduct Problem Behavior: Standardization of a Behavioural Rating Scale with Adolescents,” Journal of Clinical Child Psychology, 12(3), 347-354.

Fenwick, E, B. O’Brien and A. Briggs (2004) "Cost-Effectiveness Acceptability Curves - Facts, Fallacies and Frequently Asked Questions," Health Economics, Vol. 13, 405-415.

Fergusson, D., Horwood L. and Ridder, E., (2005) "Show me the child at Seven: The Consequences of Conduct Problems in childhood for Psychosocial functioning in Adulthood,” Journal of Child Psychology and Psychiatry, 46(8), pp. 837-849.

Gregg, P. and S. Machin (1999) 'Childhood Disadvantage and Success or Failure in the Labour Market', in D. Blanchflower and R. Freeman (eds.) Youth Employment and Joblessness in Advanced Countries, National Bureau of Economic Research, Cambridge, MA.

Gannon, B, E. O'Shea and E. Hudson (2007) “The Economic Costs of Falls and Fractures in People aged 65 and over in Ireland,” Working paper. Irish Center for Social Gerentology, NUI Galway. 
Harmon, C. and B. Nolan (2001) "Health insurance and Health Service Utilzations in Ireland,” Health Economics, 10, pp. 135-145.

Heckman, J (2000), “Policies to Foster Human Capital,” in Research in Economics, 54, 3-56.

Heckman, J. R. LaLonde and J. Smith (1999) "The Economics and Econometrics of Active Labour Market Programs,” in O.Ashenefelter and D. Card (eds) Handbook of Labour Economics.

Hutchings, J., E. Lane and J. Kelly (2004), "Comparison of Two Treatments for Children with Severely Disruptive Behaviours: A Four-Year Follow-Up," Behavioural and Cognitive Psychotherapy, 32, pp. 15-30.

Irish Prison Service Annual Report 2007, available online at http://www.irishprisons.ie/documents/IPS_AR_2007.pdf.

Kazdin, A. (1989) "Hospitilization of Antisocial Children: Clinical course followup status and predictors of outcome," Advances in Behavioural Research Therapy, 11, pp. 1-67.

Kiernan, G, N. Axford, M. Little, C. Murphy, S. Greene, M. Gormley (2008), "The School Readiness of Children Living in A Disadvantaged Area in Ireland," Journal of Early Childhood Research, 6(2), pp. 119-144.

Lewit, E. and L. Baker (1995) "School Readiness," The Future of Children, 5(2), pp. 128-39.

Lothgren, M. and N. Zethraeus (2000), "Definition, Interpretation and Calculation of Cost-Effectiveness Acceptability Curves,” Health Economics, Vol. 9, pp. 623630.

Love, J., E. Kisker, C. Ross, P. Schochet, J. Brooks-Gunn, D. Paulsell, K. Boller, J. Constantine, C. Vogel, A Fuligni, C. Bradley-Smith (2004) Making a Difference in the Lifes of Infants and Toddlers and their Families: The Impact of Early Head Start, Vol. 1 Final Report. Mathematica Policy Research.

Madden, D, Nolan, A. and B. Nolan (2005), "GP Reimbursement and visiting Behaviour in Ireland,” Health Economics, 14, pp. 1047-1060.

Miech, R, A. Caspi, T. Moffitt, B. Wright (1999), "Low socioeconomic Status and Mental Disorders: A longitudinal Study of Selection and Causation During Young Adulthood,” American Journal of Sociology, vol. 104, 4, 1096-1131. 
Muntz, R, J. Hutchings, R.T. Edwards, B. Hounsome and A. O’Ceilleachair (2004), "Economic Evaluation of Treatments for Children with Severe Behavioural Problems," The Journal of Mental Health Policy and Economics, Vol. 7, pp. 177-189.

Raikou, M. A. Gray, A. Briggs, R.Stevens, C.Cull, A. McGuire, P.Fenn, I.Stratton, R.Holman, and R.Turner. (1998) "Cost effectiveness analysis of improved blood pressure control in hypertensive patients with type 2 diabetes: UKPDS 40" British Medical Journal; 317:720-726.

Scott, S. M. Knapp, J. Henderson and B. Maughan, (2001) "Financial Cost of Social Exclusion: follow-up study of antisocial children into adulthood," British Medical Journal, 323, pp. 1-5.

Stinnett A. and J. Mullahy (1998) "Net Health Benefits: A New Framework for analyzing Uncertainty in Cost Effectiveness analysis,” Medical Decision Making, 18, S68-S80.

UNICEF (2007) An Overview of Child Well-Being in Rich Countries

UKATT Research Team (2005) "Cost Effectiveness Treatment for alcohol Problems: findings of the randomized UK alcohol treatment trial (UKATT)" British Medical Journal ; 331:544.

Van Hout, B, J. Maiwenn, G. Gordon and F. Rutten (1994), "Costs, Effects and C/ERatios alongside a Clinical Trial,” Health Economics, Vol. 3, pp. 309-319.

Webster-Stratton, C., J. Rinaldi and J. Reid (2009), "Long-Term Outcomes of Inredible Years Parenting Program: Predictors of Adolescent Adjustment," http://www.incredibleyears.com/library/items/long-term-outcomes-of-iy-parentingpgrm_7-7-09.pdf 